\title{
The Effect of Botulinum Toxin on the Amount of Sialorrhea in Patients With Neurologic Diseases
}

\author{
Seyed Ehsan Mohammadianynejad ${ }^{1,{ }^{*}}$; Davood Kashipazha ${ }^{1}$; Afshin Rezazadeh ${ }^{1}$; Mojtaba \\ Khademian Ghadikolaii ${ }^{2}$; Mehdi Masoudi Moqaddam ${ }^{2}$; Shahram Tarahomi ${ }^{2}$; Fatemeh Sadr ${ }^{2}$; \\ Ali Nakhostin Mortazavi ${ }^{2}$; Seyed Navid Naghibi ${ }^{1}$ \\ ${ }^{1}$ Golestan Hospital, Faculty of Medicine, Ahvaz Jundishapur University of Medical Sciences, Ahvaz, IR Iran \\ ${ }^{2}$ Neurology Department, Golestan Hospital, Ahvaz Jundishapur University of Medical Sciences, Ahvaz, IR Iran \\ *Corresponding author: Seyed Ehsan Mohammadianynejad, Golestan Hospital, Faculty of Medicine, Jundishapur University of Medical Sciences, Ahvaz, IR Iran. Tel: +98-9127107299, \\ E-mail: kashi-d@ajums.ac.ir
}

Received: April 12, 2015; Accepted: April 13, 2015

\begin{abstract}
Background: Drooling is an annoying problem in some neurologic and systemic diseases. Injecting botulinum toxin in the salivary glands is one of the most effective and safest treatments.

Objectives: This study was conducted to evaluate the effect of botulinum toxin on the amount of sialorrhea in patients with neurologic diseases.

Materials and methods: This study included ten patients and 60 units of botulinum toxin type A (Dysport) were injected in any submandibular gland and 120 units were injected in any parotid gland bilaterally under the ultrasonographic guide. To check drooling, daily consumption of tissue was counted and it was cheeked once before injection and at six, 12, 18, and 24 weeks after injection; then the results were compared.

Results: In this study, the effect of Dysport on the amount of drooling of the participants at the sixth, 12th, and 18th weeks after treatment was significantly decreased (P value of 0.00016, 0.0001, and 0.00011, respectively). However, after 24 weeks, this difference was not significant $($ Pvalue $=0.15$ )

Conclusions: These finding showed that Dysport can be significantly effective in reducing the amount of saliva for 18 weeks.
\end{abstract}

Keywords: Dysport; Drooling; Sialorrhea

\section{Background}

Drooling is a common problem in neurologic and systemic diseases and is seen in approximately $10 \%$ of patients with chronic neurologic diseases such as cerebral palsy, Parkinson's disease, amyotrophic lateral sclerosis, and posttraumatic encephalopathy (1). Problems such as wetness of the skin around the mouth can cause secondary bacterial infection. It can also be accompanied by impaired speech and nutrition, lead to social problems, and reduce the patient's quality of life. Salivary glands are controlled by the autonomic nervous system mediated by cholinergic and adrenergic nerve terminals; it is dominantly under the control of parasympathetic cholinergic nerves. In these patients, about $1.5 \mathrm{~L}$ of saliva is secreted from three pairs of salivary gland per day. Submandibular glands, parotid glands, and sublingual glands are responsible for $95 \%$ of the total secretion and the remainder is responsible for about $5 \%$ of the total salivary secretion (2). In recent years, some reports have shown the effects of botulinum toxin on reducing the severity of sialorrhea and drooling (3-5). This toxin is produced by an anaerobic gram-negative bacterium called Clostridium botulinum (6). Its function is based on inhibition of acetylcholine secretion in the presynaptic level. It leads to local chemical denervation and failure of neuronal activity in the target organ $(7,8)$. In one study, the most effective protocol was seen in injection of 20 units of botulinum toxin in any submaxillary gland and 30 units of toxin in parotid gland (3). In a clinical trial conducted in 2006, Shetty et al. (4) treated eight patients with considerable sialorrhea by injecting 30 units of botulinum toxin type A (BotoxA) to submandibular gland on both sides in six patients and injecting 60 units in two other patients with ultrasonography guide. Among treated patients, six patients experienced a considerable reduction of salivation and one patient recovered to some extent, but the injection of Botox did not control sialorrhea in one patient. Moreover, no complication was reported. In Brazil in 2003, Carod Artal treated three patients with motor nerve diseases such as Parkinson and cerebral infarct who had sialorrhea by injection of Transdermal botulinum toxin

Copyright @ 2015, Ahvaz Jundishapur University of Medical Sciences. This is an open-access article distributed under the terms of the Creative Commons Attribution-NonCommercial 4.0 International License (http://creativecommons.org/licenses/by-nc/4.0/) which permits copy and redistribute the material just in noncommercial usages, provided the original work is properly cited. 
type A in parotid gland. A total of 10 to 20 units of Botox were injected in any four points in each patient (two points in each gland). At first, they were evaluated by sialorrhea scale method before injection and then at week six after injection. Before treatment, all three patient got sialorrhea score of five considering the severity of sialorrhea and obtained score four considering the numbers of sialorrhea. After treatment, the severity and number of sialorrhea in two patients decreased to score two and in third patient, these factors decreased to score three. No complication was seen during treatment and follow-up period (5).

\section{Objectives}

This study was conducted to evaluate the effect of botulinum toxin on the amount of sialorrhea in patients with neurologic diseases.

\section{Materials and Methods}

\subsection{Method of Implementation and Suitable Tech- niques}

This clinical trial was conducted on patients with neurologic disease with drooling complication. The patients presented to Neurology Department of Golestan Hospital, Ahvaz, Iran. We injected 60 units of botulinum toxin A (Dysport, Ipsen, Maidenhead, the United Kingdom) in each submandibular gland and 120 units in each parotid gland under ultrasonography guide. To check drooling in patients, the number of consumed tissues was counted. The number of consumed tissues that was made available to patients in ten-tissue packages was evaluated once before injection and then at six, 12, 18, and 24 weeks after injection. The information about patients was recorded in the questionnaire. To compare the mean before and after intervention among ten subjects by using pilot study and by considering $\beta=0.2$ and $\alpha=0.05$, the mean number of the consumed tissues was equal to $668.5 \pm 69.5$ before injection and it changed to $68.9 \pm 70.18$ after injection. Finally the sample volume was counted equal to ten subjects. Inclusion criteria were age of 10 to 85 years with any neurologic disorder complaining of sialorrhea. Exclusion criteria were as follows:1) having any problem of neuromuscular junction. 2) pregnancy or breastfeeding. 3) history of any tumoral or inflammatory problems of salivary glands. 4) infection at the injection site. Dysport was injected to 12 subjects at first, out of which two patients were excluded from the study due to emigration and the remaining cases underwent treatment according to the mentioned protocol.

\section{Results}

As mentioned before, continuous drooling causes serious health and psychological problems in patients and their nurses. Eight patients had Parkinson's disease and two had cerebral palsy. The mean age of participants was $62.1 \pm 20.78$ years (range, $24-84$ years). Six subjects (60\%) were male and 4 (40\%) were female. As shown in Table 1, Dysport injection was accompanied by a significant change in reduced rate of consumed tissue in patients, during the comparison between baseline and six, 12, and 18 weeks after treatment. However, there was no significant difference between the consumption rate of tissue before treatment and 24 weeks after treatment. The maximum difference in consuming tissue by patients was observed between the baseline and 12 weeks after using the Dysport, and then the maximum benefit was seen at six and 18 weeks, consecutively (Table 2).

Table 1. Comparison of Tissue Packages Consumption by Participants at Baseline and at Six, Twelve, Eighteen, and TwentyFour Weeks After Treatment $(\mathrm{n}=10)$

\begin{tabular}{lc}
\hline Variables & Mean \pm SD \\
\hline Before treatment & $293 \pm 13.38$ \\
\hline 6 weeks after treatment & $17.9 \pm 14.84$ \\
\hline 12 weeks after treatment & $14.7 \pm 12.11$ \\
\hline 18 weeks after treatment & $47.3 \pm 18.15$ \\
\hline 24 weeks after treatment & $265 \pm 19.02$ \\
\hline
\end{tabular}

Table 2. The Mean Difference Rate of Consumption of Tissue Packager Between Baseline and Six, Twelve, Eighteen, and Twenty-Four Weeks After Treatment ${ }^{\mathrm{a}}$

\begin{tabular}{lcc}
\hline Variables & The Mean of Differences & P Value \\
\hline $\begin{array}{l}\text { Before treatment } \\
\text { and 6th week }\end{array}$ & $2.75 \pm 34.33$ & 0.00011 \\
$\begin{array}{l}\text { Before treatment } \\
\text { and 12th week }\end{array}$ & $2.78 \pm 20.85$ & 0.00001 \\
$\begin{array}{l}\text { Before treatment } \\
\text { and 18thweek }\end{array}$ & $2.45 \pm 27.15$ & 0.00016 \\
$\begin{array}{l}\text { Before treatment } \\
\text { and 24th week }\end{array}$ & $2.80 \pm 26.63$ & 0.15 \\
\hline
\end{tabular}

a Data are presented as mean \pm SD.

\section{Discussion}

In 2008 in Portugal, Costa et al. (9) evaluated the effect of botulinum toxin type B on the sialorrhea of 16 patients during a clinical trial. They treated the patients by injecting 100 units to parotid gland and 25 units to submandibular with the help of anatomical symptoms and by reviewing the severity and disability of sialorrhea one month after injection. To evaluate more, they asked patients to complete questionnaires associated with the amount of drooling and their quality of life and they also performed objective evaluations including cotton, roll weight, and the number of consumed tissues. Gilio et al. (10) treated 26 patients with amyotrophic lateral sclerosis during a prospective study by injection of botulinum toxin type $\mathrm{A}$ 
in parotid glands on both sides, these patients also had bulbar symptoms. Two week after injection, the severity of sialorrhea was evaluated subjectively and objectively. A group of healthy people also participated in this study as a control group. To evaluate the possible effects of toxin on the muscles that were not injected, patients were placed under electrophysiologic tests by compound muscle action potentials (CMAPs) amplitude comparison. After injection, the severity of sialorrhea was decreased in 23 patients out of 26 patients who were under treatment. Two patients were dissatisfied with the dry mouth. No change was seen in CMAPs amplitude and it showed ineffectiveness of botulinum toxin on face and masticatory muscles in the patients without an injection. Scheffer et al. (11) evaluated 131 infants with cerebral palsy or other nonprogressive neurologic diseases. These patients had drooling with medium to severe intensity. Then patients were evaluated by direct observational drooling quotient scores (DQ) and caretaker visual analogue scale (VAS) methods. Finally, response to treatment was seen in $46.6 \%$ of infants. The mean DQ score reached to 15 after two months and to 19 after eight months. The mean VAS score reached to 53 after two months and to 66 after eight months.

Apparently, we need stronger evidence to prove the effect of botulinum toxin on the treatment of drooling. In this study, the effect of Dysport on decreasing the amount of drooling of patients at six, 12, and 18 weeks after the treatment was significant. However, it seems that the beneficial effects of medicine on the amount of drooling were significantly reduced after 24 weeks.

In conclusion, it is suggested that the sample size should be larger in future study and the comparison of salivary reduction after injection in parotid and submandibular glands should be conducted with injection in just parotid gland.

\section{References}

1. Smith RA, Goode RL. Current concepts: sialorrhea. N Engl J Med. 1970;283(17):917-8.

2. Lew KM, Younis RT, Lazar RH. The current management of sialorrhea. Ear Nose Throat J. 1991;70(2):99-105.

3. Breheret R, Bizon A, Jeufroy C, Laccourreye L. Ultrasound-guided botulinum toxin injections for treatment of drooling. Eur Ann Otorhinolaryngol Head Neck Dis. 2011;128(5):224-9.

4. Shetty S, Dawes P, Ruske D, Al-qudah M, Lyons B. Botulinum toxin type-A (Botox-A) injections for treatment of sialorrhoea in adults: a New Zealand study. N Z Med J. 2006;119(1240):U2129.

5. Carod Artal FJ. [Treatment of sialorrhoea in neurological diseases with trans-dermic injections of botulinum toxin type $A$ in the parotid glands]. Neurologia. 2003;18(5):280-4.

6. Thant ZS, Tan EK. Emerging therapeutic applications of botulinum toxin. Med Sci Monit. 2003;9(2):RA40-8.

7. Bushara KO. Sialorrhea in amyotrophic lateral sclerosis: a hypothesis of a new treatment--botulinum toxin A injections of the parotid glands. Med Hypotheses. 1997;48(4):337-9.

8. Naumann M, Jost W. Botulinum toxin treatment of secretory disorders. Mov Disord. 2004;19 Suppl 8:S137-41.

9. Costa J, Rocha ML, Ferreira J, Evangelista T, Coelho M, de Carvalho $\mathrm{M}$. Botulinum toxin type-B improves sialorrhea and quality of life in bulbaronset amyotrophic lateral sclerosis. J Neurol. 2008;255(4):545-50.

10. Gilio F, Iacovelli E, Frasca V, Gabriele M, Giacomelli E, Picchiori F, et al. Botulinum toxin type A for the treatment of sialorrhoea in amyotrophic lateral sclerosis: a clinical and neurophysiological study. Amyotroph Lateral Scler. 2010;11(4):359-63.

11. Scheffer AR, Erasmus C, van Hulst K, van Limbeek J, Jongerius PH van den Hoogen FJ. Efficacy and duration of botulinum toxin treatment for drooling in 131 children. Arch Otolaryngol Head Neck Surg. 2010;136(9):873-7. 